\title{
Costs and health care resource utilization among chronic obstructive pulmonary disease patients with newly acquired pneumonia
}

This article was published in the following Dove Press journal:

ClinicoEconomics and Outcomes Research

16 July 2014

Number of times this article has been viewed

\author{
Junji Lin' \\ Yunfeng $\mathrm{Li}^{2}$ \\ Haijun Tian ${ }^{2}$ \\ Michael J Goodman' \\ Susan Gabriel² \\ Tara Nazareth ${ }^{2}$ \\ Stuart J Turner ${ }^{2,3}$ \\ Stephen Arcona ${ }^{2}$ \\ Kristijan H Kahler ${ }^{2}$ \\ 'Department of Pharmacotherapy, \\ University of Utah, Salt Lake City, \\ UT, USA; ${ }^{2}$ Health Economics and \\ Outcomes Research, Novartis \\ Pharmaceuticals Corporation, \\ East Hanover, NJ, USA; ${ }^{3}$ Ernest \\ Mario School of Pharmacy, Rutgers \\ University, New Brunswick, NJ, USA
}

Correspondence: Junji Lin

Former Health Economics and

Outcomes Research Fellow, Novartis

Pharmaceuticals Corporation, Hanover,

NJ, USA

Tel +80I 7507797

Email junjilin@gmail.com
Background: Patients with chronic obstructive pulmonary disease (COPD) are at increased risk for lung infections and other pathologies (eg, pneumonia); however, few studies have evaluated the impact of pneumonia on health care resource utilization and costs in this population. The purpose of this study was to estimate health care resource utilization and costs among COPD patients with newly acquired pneumonia compared to those without pneumonia.

Methods: A retrospective claims analysis using Truven MarketScan ${ }^{\circledR}$ Commercial and Medicare databases was conducted. COPD patients with and without newly acquired pneumonia diagnosed between January 1, 2004 and September 30, 2011 were identified. Propensity score matching was used to create a 1:1 matched cohort. Patient demographics, comorbidities (measured by Charlson Comorbidity Index), and medication use were evaluated before and after matching. Health care resource utilization (ie, hospitalizations, emergency room [ER] and outpatient visits), and associated health care costs were assessed during the 12-month follow-up. Logistic regression was conducted to evaluate the risk of hospitalization and ER visits, and gamma regression models and two-part models compared health care costs between groups after matching.

Results: In the baseline cohort $(\mathrm{N}=467,578)$, patients with newly acquired pneumonia were older (mean age: 70 versus [vs] 63 years) and had higher Charlson Comorbidity Index scores (3.3 vs 2.6) than patients without pneumonia. After propensity score matching, the pneumonia cohort was nine times more likely to have a hospitalization (odds ratio; $95 \%$ confidence intervals [CI] $=9.2 ; 8.9,9.4$ ) and four times more likely to have an ER visit (odds ratio; 95\% CI $=4.4 ; 4.3,4.5$ ) over the 12-month follow-up period compared to the control cohort. The estimated 12-month mean hospitalization costs (\$14,353 [95\% CI: \$14,037-\$14,690]), outpatient costs $(\$ 6,891$ [95\% CI: \$6,706-\$7,070]), and prescription drug costs (\$1,104 [95\% CI: \$1,054-\$1,142]) were higher in the pneumonia cohort than in the control cohort.

Conclusion: This study demonstrated elevated health care resource use and costs in patients with COPD after acquiring pneumonia compared to those without pneumonia.

Keywords: COPD, health care costs, cost effectiveness/economics, outcomes research

\section{Background}

Chronic obstructive pulmonary disease (COPD), a life-threatening progressive disease, is characterized by chronic airflow limitations that are the result of a combination of obstructive bronchiolitis (small airway disease) and emphysema (parenchymal destruction). ${ }^{1} \mathrm{Up}$ to $50 \%$ of patients with COPD are prescribed inhaled corticosteroids (ICS), even though an increased risk of pneumonia has been widely recognized with their use. ${ }^{2-5}$ In a large retrospective cohort analysis of patients with COPD, the incidence rate of pneumonia for patients treated with an ICS was 1.5 times higher than in patients not using an ICS. ${ }^{2}$ In another large case-control study, the use of ICS was 
associated with a $70 \%$ increase in the rate of hospitalization for pneumonia. ${ }^{3}$ Risk factors for pneumonia associated with COPD include age $\geq 55$ years, forced expiratory volume in 1 second $<50 \%$ predicted, protracted COPD exacerbations, worse dyspnea, and body mass index $<25 \mathrm{~kg} / \mathrm{m}^{2}{ }^{6,7}$

COPD is an important and growing cause of morbidity and mortality, ${ }^{8}$ with pneumonia as a complication that is associated with additional health care utilization and costs. ${ }^{7,9,10}$ In a study of community-acquired pneumonia in working-age adults, pneumonia associated with COPD resulted in mean excess annualized medical costs (hospitalization, outpatient, pharmacy) of US\$17,039 and an excess annualized productivity loss (absenteeism, short-term disability) of $\$ 6,454$ versus (vs) matched controls without pneumonia. ${ }^{11}$ These excess medical costs were almost two times greater for patients with COPD and pneumonia than for patients with pneumonia without any comorbidities. Furthermore, disability resulting from pneumonia episodes that led to missed work and other indirect costs have been found to be notably higher in COPD patients with pneumonia. ${ }^{11}$

Although a number of studies have reviewed the care burden of either COPD or pneumonia, no studies have quantified the burden of pneumonia in patients with COPD. ${ }^{11-14}$ Costs for patient care associated with COPD are assumed to increase with the development of pneumonia, though few studies have directly investigated this question in a real-world setting. ${ }^{15}$ This study compared health care resource utilization and costs among COPD patients with newly acquired pneumonia compared to those without pneumonia using data from commercial health insurance plans.

\section{Methods}

\section{Data sources}

This retrospective claims analysis used data from the Truven Health MarketScan ${ }^{\circledR}$ Commercial Claims and Encounters (CCE) (Truven Health Analytics, Inc., Ann Harbor, MI, USA) and Medicare Supplemental and Coordination of Benefits (MSCOB) databases to identify patients with COPD between January 1, 2004 and September 30, 2011. These databases represent the health care experience of several million enrollees in commercial health insurance plans sponsored by more than 300 employers in the United States, and include monthly enrollment data, hospitalization and outpatient medical claims, outpatient prescription drug claims, and eligibility information. ${ }^{16}$ For study populations included in these databases, medical claims are linked to outpatient prescription drug claims and person-level enrollment data through the use of unique patient identifiers. These databases provide not only standard demographic variables (ie, age, sex, employment status, geographic location), but also detailed cost (payment) and health care utilization information for health care services performed in both inpatient and outpatient settings. ${ }^{16}$ All study data were accessed using techniques compliant with the Health Insurance Portability and Accountability Act of 1996; as such, no identifiable protected health information was extracted during the course of the study, and this study did not therefore require informed consent or institutional review board approval.

\section{Sample selection}

Patients were included if they had at least one COPD inpatient or emergency room (ER) claim or two COPD outpatient claims ( $>1$ day apart and $<12$ months apart) between January 1, 2004 and September 30, 2011. Diagnosis of COPD was identified according to the following International Classification of Diseases, Ninth Revision, Clinical Modification (ICD-9-CM) ${ }^{17}$ claims or two ICD9-CM outpatient claims ( $>1$ day apart and $<12$ months apart): 491 (chronic bronchitis); 491.1 (mucopurulent chronic bronchitis); 491.2 (obstructive chronic bronchitis); 491.21 (obstructive chronic bronchitis with acute exacerbations); 491.22 (obstructive chronic bronchitis with acute bronchitis); 491.8 (chronic bronchitis not elsewhere classified [NEC]); 491.9 (chronic bronchitis not otherwise specified); 492 (emphysema or emphysematous bleb); 492.8 (emphysema NEC); or 496 (chronic airway obstruction NEC). Patients who had an asthma, lung cancer, or cystic fibrosis diagnosis within the study period were excluded. In addition, patients 39 years or younger were also excluded because patients $<40$ years are not considered at high risk for COPD (Figure 1). ${ }^{18}$

Patients were then grouped into two cohorts: the pneumonia cohort (patients with a diagnosis of newly acquired pneumonia; $n=308,083$ ) and the control cohort (patients with no diagnosis of pneumonia; $n=962,764$ ) for further cohort selection based on additional exclusion/inclusion criteria. For the pneumonia cohort, an index date was assigned as the first date of a diagnosis of pneumonia. If there was a diagnosis of bronchitis within 30 days prior to the date of the pneumonia diagnosis, the index date was reassigned to the date of the bronchitis diagnosis since it was likely to be the same episode of illness. For the control cohort, since no pneumonia diagnosis was documented throughout the entire enrollment period, the index date was represented as one physician visit (randomly chosen if multiple visits existed) between January 1, 2005 and 


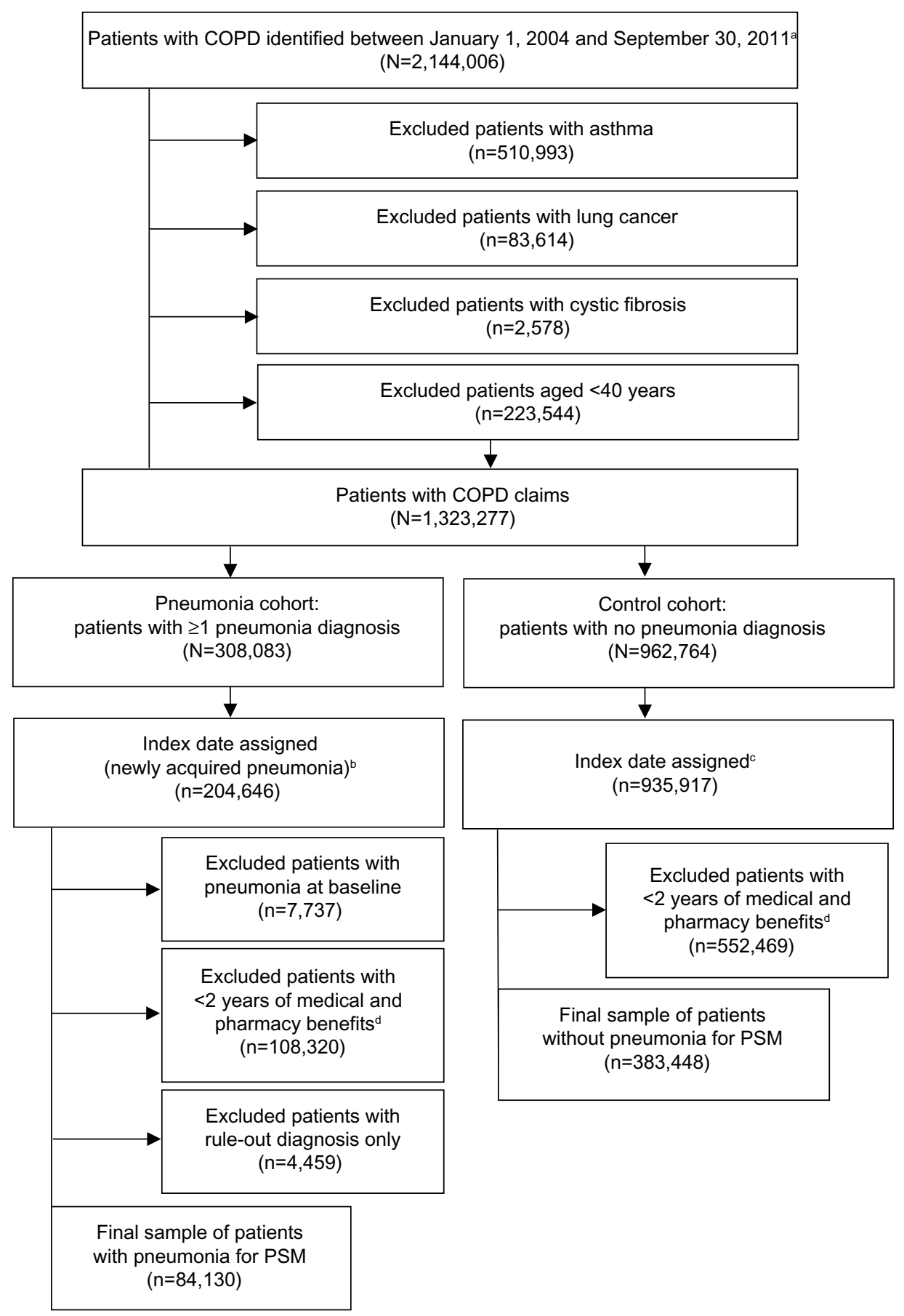

Figure I Patient selection flowchart.

Notes: aldentification determined by COPD-related admissions or emergency room visits or two or more COPD-related office visits on different dates; bindex date for newly acquired pneumonia was after COPD diagnosis, and was determined to be the date of any bronchitis claim within 30 days of the first pneumonia diagnosis or of the first pneumonia claim if no bronchitis claims; 'randomly assigned physician visit date as index date during the study enrollment period and patients with index date before COPD diagnosis were excluded; ${ }^{\mathrm{d}}$ welve-month baseline and $\mathrm{I} 2$ months of follow-up.

Abbreviations: COPD, chronic obstructive pulmonary disease; PSM, propensity score matching.

September 30, 2011. Twelve months prior to the index date and 12 months after the index date were designated, and only patients with a full 2 years of medical and pharmacy benefits during this period were retained for both cohorts. In addition, the patients in the pneumonia cohort who had any pneumonia diagnosis in the baseline period or had only a rule-out diagnosis were excluded in the follow-up period. The rule-out was defined as claims for laboratory, pathology, or radiology services for screening purposes, and was not used to identify individuals with a specific condition. ${ }^{16}$ 
A final sample of 84,130 patients in the pneumonia cohort and 383,448 patients in the control cohort were included for propensity score matching (PSM).

Baseline patient demographics and health care resource utilization (age, sex, health insurance status, geographical region, employment status, medication use, hospitalizations, outpatient and ER visits, and Charlson Comorbidity Index [CCI]) were collected at baseline. ${ }^{19}$

\section{Outcome measures}

The study outcomes included all-cause and pneumoniarelated health care resource utilization and adjusted costs. Health care resource utilization during the 12-month follow-up period included hospitalizations and ER visits. The odds ratios (ORs) were reported for all-cause and pneumonia-related health care resource utilization. Allcause and pneumonia-related costs during this time included hospitalization costs, outpatient medical costs, and outpatient pharmacy costs.

\section{Statistical analysis}

Patients in the pneumonia cohort were matched 1:1 with patients in the control cohort using PSM methodology. Patient demographics, comorbidities measured by CCI, health care resource utilization, and medication use were evaluated before and after matching. Variables included in the initial PSM were age, sex, insurance type, geographical region, employment status, index year, time of year (summer [May-October)]/winter [November-April]), CCI score, medication used, and health care utilization (hospitalizations, ER visits, and outpatient visits) at the baseline period. For balance diagnostics in the PSM model, absolute standardized difference $^{20}$ was used to compare the mean of continuous and binary variables between treatment groups (multilevel categorical variables were represented using a set of binary indicator variables). For outcome variables, $\chi^{2}$ tests were performed for categorical variables and Student's $t$-tests were used for continuous variables.

Health care resource utilization (ie, hospitalizations, ER visits, and outpatient visits) and associated health care costs were assessed during the 12-month follow-up period. Multivariate logistic regression models were used to assess the association of pneumonia with dichotomous indicators of hospitalization and ER use within the 12-month follow-up period. Generalized linear modeling with gamma distribution and log-link function was used to test for differences in health care utilization costs in the follow-up period. To account for data that contained too many zero cost values, a two-part model was used (part 1 with logistic regression to examine the association between hospitalization costs from COPD [ $>0$ vs 0] and part 2 with generalized linear modeling with log-link function for pneumonia-related positive hospitalization costs). The marginal effects in terms of dollars and bootstrapping 95\% confidence intervals (CIs) were reported. ${ }^{21}$ All analyses were conducted using SAS software (v 9.2; SAS Institute Inc., Cary, NC, USA).

\section{Results Sample baseline characteristics}

Between January 1, 2004 and September 30, 2011, a total of 2,144,006 COPD patients were identified. Of the 2,144,006 patients identified with COPD, a total of 1,323,277 patients were included after applying the inclusion and exclusion criteria mentioned above and as depicted in Figure 1. After inclusion and exclusion criteria were applied, the total population with a COPD claim was 467,578: 84,130 patients in the pneumonia cohort and 383,448 patients in the control cohort before PSM (Figure 1).

In the baseline period before matching, patients in the pneumonia cohort were older (mean age: 70 vs 63 years) and had higher CCI scores (3.3 vs 2.6) than patients in the control cohort. The pneumonia cohort was generally more likely to be on medications related to lung disease, including antibiotics (41.5\% vs 29.7\%); and ICS with or without long-acting $\beta$-agonists ( $16.3 \%$ vs $8.4 \%$ ). Patients in the pneumonia cohort were also more likely to be hospitalized $(38.9 \%$ vs $24.7 \%$ ) or have ER visits (46.3\% vs $34.2 \%)$ compared with the control (Table 1). The control cohort was more likely to be working (20.9\% vs $11.2 \%)$ than the pneumonia cohort, which was more likely to be retired (55.1\% vs $36.9 \%)$. After matching, each cohort contained 84,130 patients, no baseline covariates were different between groups based on standardized differences, and all absolute standard differences were less than 0.1 (Table 1). ${ }^{20}$

\section{Multivariate analysis and PSM}

Multivariate logistic regression showed that significantly higher all-cause ORs (95\% CIs) for hospitalizations and ER visits were reported in patients with pneumonia vs those without $(\mathrm{OR}=9.2$ [95\% CI: 8.9, 9.4] and OR $=4.4[95 \%$ CI: 4.3, 4.5], respectively; both $P<0.001$ ) (Table 2). The risk of outpatient visits was not statistically significantly different between the two cohorts (OR $=1.1$ [95\% CI: 0.9, $1.3]$; $P=0.5$ ). Higher costs were associated with pneumonia, and after adjusting for baseline demographic and clinical characteristics, cost differences $(95 \% \mathrm{CI})$ were $\$ 14,353$ 
Table I Baseline characteristics before and after PSM

\begin{tabular}{|c|c|c|c|c|c|c|}
\hline & \multicolumn{3}{|c|}{ Before PSM $(\mathrm{N}=467,578)$} & \multicolumn{3}{|l|}{ After PSM } \\
\hline & $\begin{array}{l}\text { Pneumonia } \\
\text { cohort } \\
(n=84,130)\end{array}$ & $\begin{array}{l}\text { Control } \\
\text { cohort } \\
(n=383,448)\end{array}$ & $\begin{array}{l}\text { Absolute } \\
\text { standardized } \\
\text { difference }^{a}\end{array}$ & $\begin{array}{l}\text { Pneumonia } \\
\text { cohort } \\
(n=84,130)\end{array}$ & $\begin{array}{l}\text { Control } \\
\text { cohort } \\
(n=84,130)\end{array}$ & $\begin{array}{l}\text { Absolute } \\
\text { standardized } \\
\text { difference }^{\mathrm{a}}\end{array}$ \\
\hline Age (years), mean (SD) & $70.1(12.5)$ & $62.7(12.3)$ & 0.592 & $70.1(12.5)$ & $70.2(12.3)$ & -0.011 \\
\hline Sex, n (\%) & & & 0.061 & & & 0.007 \\
\hline Female & $4 I, 040(48.8)$ & $198,786(51.8)$ & & $4 I, 040(48.8)$ & $4 I, 353(49.2)$ & \\
\hline Male & $43,090(51.2)$ & $184,662(48.2)$ & & $43,090(51.2)$ & $42,777(50.9)$ & \\
\hline \multicolumn{7}{|l|}{ Health insurance, $n(\%)$} \\
\hline Non-FFS & $8,680(10.3)$ & $49,629(12.9)$ & -0.082 & $8,680(10.3)$ & $8,353(9.9)$ & 0.013 \\
\hline FFS & $73,469(87.3)$ & $324,268(84.6)$ & 0.080 & $73,469(87.3)$ & $73,968(87.9)$ & -0.018 \\
\hline Missing & $\mathrm{I}, 98 \mathrm{I}(2.4)$ & $9,55 \mathrm{I}(2.5)$ & -0.009 & $\mathrm{I}, 98 \mathrm{I}(2.4)$ & $\mathrm{I}, 809(2.2)$ & 0.014 \\
\hline \multicolumn{7}{|l|}{ Regions in the USA, $n(\%)$} \\
\hline Northeast & I0,04| (II.9) & $52,842(13.8)$ & -0.055 & $10,04 \mid(11.9)$ & $9,862(11.7)$ & 0.007 \\
\hline North Central & $32,365(38.5)$ & $122,032(3 \mid .8)$ & 0.140 & $32,365(38.5)$ & $31,937(38.0)$ & 0.010 \\
\hline South & $29,112(34.6)$ & I44,937 (37.8) & -0.067 & $29,112(34.6)$ & $30,219(35.9)$ & -0.028 \\
\hline West & II,267 (13.4) & $55,235(14.4)$ & -0.029 & II,267 (13.4) & $10,716(12.7)$ & 0.019 \\
\hline Unknown & $1,345(1.6)$ & $8,402(2.2)$ & -0.043 & $1,345(1.6)$ & I,396 (I.7) & -0.005 \\
\hline $\mathrm{CCl}$ score, mean (SD) & $3.3(2.6)$ & $2.6(2.0)$ & 0.279 & $3.3(2.6)$ & $3.2(2.3)$ & 0.008 \\
\hline \multicolumn{7}{|l|}{ Employment status, n (\%) } \\
\hline Employed & $9,438(11.2)$ & $80,092(20.9)$ & -0.266 & $9,438(11.2)$ & $8,712(10.4)$ & 0.028 \\
\hline Retired & $46,348(55.1)$ & $14 \mid, 592(36.9)$ & 0.371 & $46,348(55.1)$ & $45,737(54.4)$ & 0.015 \\
\hline Other & $28,344(33.7)$ & $161,764(42.2)$ & -0.176 & $28,344(33.7)$ & $29,68 \mathrm{I}(35.3)$ & -0.033 \\
\hline Summer (May-October), n (\%) & $33,080(39.3)$ & $193,842(50.6)$ & -0.227 & $33,080(39.3)$ & 32,45 I (38.6) & 0.015 \\
\hline \multicolumn{7}{|l|}{ Medication use, $\mathrm{n}(\%)$} \\
\hline Antibiotics & $34,892(41.5)$ & II3,90| (29.7) & 0.248 & $34,892(41.5)$ & $32,|7|(38.2)$ & 0.066 \\
\hline ICS & $3,524(4.2)$ & $8,201(2.1)$ & 0.117 & $3,524(4.2)$ & $3,004(3.6)$ & 0.032 \\
\hline ICS/LABA & $10,153(12.1)$ & $24,108(6.3)$ & 0.201 & $10,153(12.1)$ & $8,844(10.5)$ & 0.049 \\
\hline LABA & $1,356(1.6)$ & $2,837(0.7)$ & 0.081 & $1,356(1.6)$ & $\mathrm{I}, 157(1.4)$ & 0.020 \\
\hline LTRA & $3,450(4.1)$ & $8,888(2.3)$ & 0.101 & $3,450(4.1)$ & $2,953(3.5)$ & 0.031 \\
\hline Long-acting anticholinergics & $6,94 I(8.3)$ & $17,834(4.7)$ & 0.147 & $6,941(8.3)$ & $6,021(7.2)$ & $0.04 I$ \\
\hline Mast cell stabilizer & $30(0.04)$ & $52(0.01)$ & 0.014 & $30(0.04)$ & $17(0.02)$ & 0.009 \\
\hline OCS & $14,358(17.1)$ & $38,628(10.1)$ & 0.205 & $14,358(17.1)$ & $|2,49|(\mid 4.9)$ & $0.06 \mathrm{I}$ \\
\hline SABA & $8,594(10.2)$ & $26,403(6.9)$ & 0.119 & $8,594(10.2)$ & $7,113(8.5)$ & $0.06 \mathrm{I}$ \\
\hline $\begin{array}{l}\text { Short-acting anticholinergics with/ } \\
\text { without short-acting } \beta_{2} \text {-agonists }\end{array}$ & $9,791(11.6)$ & $19,243(5.0)$ & $0.24 I$ & 9,791 (II.6) & $8,458(10.1)$ & 0.051 \\
\hline Xanthines & $1,675(2.0)$ & $2,900(0.8)$ & 0.106 & $\mathrm{I}, 675(2.0)$ & $\mathrm{I}, 444(\mathrm{I} .7)$ & 0.020 \\
\hline Index date (year), n (\%) & & & -0.357 & & & -0.005 \\
\hline 2005 & $|3,43|(16.0)$ & $36,040(9.4)$ & & $|3,43|(16.0)$ & I4,525 (I7.3) & \\
\hline 2006 & $12,612(15.0)$ & $36,506(9.5)$ & & $12,612(15.0)$ & II,877 (14.I) & \\
\hline 2007 & $|3,59|(16.2)$ & $51,440(13.4)$ & & $|3,59|(16.2)$ & $13,157(15.6)$ & \\
\hline 2008 & $13,917(16.5)$ & $64,370(16.8)$ & & $13,917(16.5)$ & $|3,12|(15.6)$ & \\
\hline 2009 & $18,570(22.1)$ & $98,867(25.8)$ & & $18,570(22.1)$ & I8,292 (21.7) & \\
\hline 2010 & $12,009(14.3)$ & $96,225(25.1)$ & & $12,009(14.3)$ & $13,158(15.6)$ & \\
\hline Hospitalizations, n (\%) & $32,723(38.9)$ & 94,599 (24.7) & 0.309 & $32,723(38.9)$ & $33,082(39.3)$ & -0.009 \\
\hline \multicolumn{7}{|l|}{ Outpatient visits, n (\%) } \\
\hline 0 & $6,046(7.2)$ & $16,536(4.3)$ & 0.124 & $6,046(7.2)$ & $6,030(7.2)$ & 0.001 \\
\hline$\leq 5$ & 24,318 (28.9) & $|37,29|(35.8)$ & 0.148 & 24,318 (28.9) & $24,366(29.0)$ & -0.001 \\
\hline$>5$ & $53,766(63.9)$ & 229,621 (59.9) & 0.083 & $53,766(63.9)$ & $53,734(63.9)$ & 0.001 \\
\hline ER visits, n (\%) & $38,989(46.3)$ & $|3|, 04 \mid(34.2)$ & 0.250 & $38,989(46.3)$ & $39,407(46.8)$ & -0.010 \\
\hline
\end{tabular}

Notes: ${ }^{\mathrm{A}} \mathrm{A}$ standardized difference that is less than absolute value 0.1 has been taken to indicate a negligible difference in the mean or prevalence of a covariate between treatment and control groups; bnon-FFS health plan included health maintenance organizations and point of service with capitation; all others coded as FFS.

Abbreviations: PSM, propensity score matching; SD, standard deviation; FFS, fee for service; CCI, Charlson Comorbidity Index; ICS, inhaled corticosteroids; LABA, longacting $\beta$-agonists; LTRA, leukotriene receptor antagonists; OCS, oral corticosteroids; SABA, short-acting $\beta_{2}$-adrenergic receptor agonists; ER, emergency room.

$(\$ 14,037, \$ 14,690), \$ 6,891(\$ 6,706, \$ 7,070)$, and $\$ 1,104$ $(\$ 1,054, \$ 1,142)$ for all-cause hospitalization, all-cause outpatient visits, and all-cause prescription costs, respectively (Table 2).
Multivariate logistic regression showed that women were $3.6 \%$ more likely than men to have a hospitalization ( $\mathrm{OR}=1.04$ [95\% CI: 1.01, 1.06], $P<0.05$ ), but $8.0 \%$ less likely to have an ER visit ( $\mathrm{OR}=0.92$ [95\% CI: 0.90, 0.94], 
Table 2 Adjusted health care resource utilization and costs for patients with and without pneumonia in follow-up period in the matched population

\begin{tabular}{|c|c|c|c|c|}
\hline Variable & $\begin{array}{l}\text { Pneumonia } \\
\text { cohort }\end{array}$ & $\begin{array}{l}\text { Control } \\
\text { cohort }\end{array}$ & $\begin{array}{l}\text { Odds ratio } \\
(95 \% \mathrm{Cl})\end{array}$ & $P$-value \\
\hline Patients, $\mathrm{n}$ & 84,130 & 84,130 & & \\
\hline \multicolumn{5}{|l|}{ Resource utilization, $n(\%)^{\mathrm{a}}$} \\
\hline All-cause hospitalizations & $59,678(70.9)$ & $18,419(21.9)$ & $9.2(8.9,9.4)$ & $<0.0001$ \\
\hline All-cause ER visits & $57,252(68.1)$ & $27,507(32.7)$ & $4.4(4.3,4.5)$ & $<0.001$ \\
\hline All-cause outpatient visits & $83,948(99.8)$ & $80,505(95.7)$ & I.I $(0.9,1.3)$ & 0.5 \\
\hline Pneumonia-specific hospitalization & $27,882(33.1)$ & Not applicable & & \\
\hline Pneumonia-specific ER visits & $28,982(34.4)$ & Not applicable & & \\
\hline Pneumonia-specific outpatient visits & $62,101(73.8)$ & Not applicable & & \\
\hline \multirow[t]{2}{*}{ Mean health care cost, US\$(SD) } & & & Cost difference & \\
\hline & & & $(95 \% \mathrm{Cl})$ & \\
\hline All-cause hospitalization & $\$ 18,209(\$ 8,325)$ & $\$ 3,856(\$ 2,035)$ & $\$ 14,353(\$ 14,037, \$ 14,690)$ & \\
\hline All-cause outpatient & $\$ 14,5 \mid 4(\$ 7,776)$ & $\$ 7,623(\$ 3,935)$ & $\$ 6,891(\$ 6,706, \$ 7,070)$ & \\
\hline All-cause prescription & $\$ 4,103(\$ 1,339)$ & $\$ 2,998(\$ 948)$ & $\$ 1,104(\$ 1,054, \$ 1,142)$ & \\
\hline
\end{tabular}

Note: ${ }^{a} n$ denotes the number of patients with health care resource utilization.

Abbreviations: $\mathrm{ER}$, emergency room; SD, standard deviation; $\mathrm{Cl}$, confidence interval.

$P<0.05$ ), and that patients $\geq 60$ years of age were $61.9 \%$ more likely than those aged 40 to 60 years to have a hospitalization (OR $=1.62[95 \% \mathrm{CI}: 1.58,1.66], P<0.05)$ and $15.0 \%$ more likely to have an ER visit (OR $=1.15[95 \% \mathrm{CI}$ : $1.12,1.18], P<0.05)$. Increased CCI was associated with more hospitalizations and ER visits (OR $=1.64[95 \% \mathrm{CI}$ : $1.61,1.68]$ and $\mathrm{OR}=1.54$ [95\% CI: $1.51,1.57]$, respectively, both $P<0.05$ ). Time of year (summer/winter) was not found to affect hospitalization statistically significantly at the 0.05 level; however, patients were $5.5 \%$ more likely to have an ER visit in the summer compared with the winter $(\mathrm{OR}=1.06$ [95\% CI: 1.03, 1.08], $P<0.05$ ) (data not shown).

\section{Discussion}

This is the first investigation into health care resource utilization and the costs associated with pneumonia in COPD patients. Our results indicate that COPD patients with newly developed pneumonia have higher health care resource utilization and/or costs in all areas explored: hospitalizations, outpatient visits, ER visits, and prescription costs. In our study, the pneumonia cohort was approximately nine times more likely to have a hospitalization and four times more likely to have an ER visit during the 12 months of follow-up. A total cost savings of $\$ 22,348$ was estimated to be associated with the prevention of pneumonia based on the sum of the mean differences of $\$ 14,353$ in inpatient costs, $\$ 6,891$ in outpatient costs, and \$1,104 in pharmacy costs between the pneumonia and control cohorts. Since an estimated 21\% of the 14.8 million patients diagnosed annually with COPD experience pneumonia, ${ }^{2,22}$ this could potentially translate into a total yearly savings of approximately $\$ 69$ billion.
Other studies have examined the economic burden in patients with community-acquired pneumonia, and the findings have reported similar results in terms of excess costs for patients with certain comorbidities (ie, asthma, diabetes, COPD, congestive heart failure) ${ }^{23,24}$ In a study by Polsky et al, ${ }^{11}$ patients with COPD had annual total costs of $\$ 30,781$ and incremental costs of $\$ 17,039$ compared to patients without COPD for total medical expenses. These costs are slightly less than our estimation of $\$ 36,825$ for total medical costs. This difference may be due to the different study periods and settings. Most importantly, our study examines the economic burden of COPD patients with newly acquired pneumonia while the previous study focused on patients with community-acquired pneumonia only.

Our study results suggest that identifying patients at greater risk for the development of pneumonia and implementing strategies to lower this risk would be important. A large evidence base exists indicating that ICS agents are associated with an increased risk of pneumonia., ${ }^{2,3} \mathrm{~A}$ recent study showed that the incidence of pneumonia was $28 \%$ higher in patients on low-dose ICS therapy, $111 \%$ higher in patients on moderate-dose ICS therapy, and $224 \%$ higher in those on highdose ICS therapy compared with patients not on ICS therapy. ${ }^{2}$ Other risk factors for pneumonia include age (over 65 years), previous severe COPD exacerbations, and comorbidities, such as congestive heart failure and dementia. ${ }^{25}$ Factors observed in the unmatched cohort of the present study confirm previous investigations, ${ }^{7-14}$ in that patients with pneumonia are older, have higher CCI scores, are more likely to be on medications related to lung disease, and are more likely to be hospitalized or have visited the ER than patients without pneumonia. To 
further mitigate the incidence of pneumonia in COPD patients, ICS use should be considered carefully and used appropriately in patients with any of these risk factors.

This analysis also highlights the importance of regular monitoring of patient symptoms and COPD clinical status. Current Global initiative for chronic Obstructive Lung Disease (GOLD) guidelines recommend key areas in the management of stable COPD, including assessment of symptoms, degree of airflow limitation using spirometry, and risk of exacerbations. ${ }^{26}$ However, GOLD further addresses advice on smoking cessation, physical activity, and influenza/ pneumococcal vaccinations. ${ }^{26}$ Furthermore, there is the potential that early patient and physician identification of an impending exacerbation may assist in treating patients at a milder exacerbation stage who may not require hospitalization, and the associated increased expenditure relative to home-based care.

Our results should be viewed in light of a number of limitations. First, due to the use of an administrative claims database, errors in reporting or missing data could have occurred using the ICD-9-CM codes for pneumonia. Despite the use of a 12-month look-back period, absolute certainty on the assigned index date as being the first pneumonia episode for a patient is not possible. Although we understand that patients with more severe disease would require additional resources, such information will need to be based on lung function tests (eg, spirometry, body plethysmography, and lung diffusion capacity), exacerbation rates, or other disease symptoms. Unfortunately, these clinical data or patient-reported outcomes are not captured in the claims databases; therefore, differences in disease severities could not be addressed in this manuscript. Another limitation of this study is that PSM can balance only measurable confounders. Differences in unmeasured confounders (eg, lifestyle risk factors, disease severity) may still exist in our cohorts. Reimbursement was not considered, which would have had an impact on absolute costs. However, because reimbursement was assumed to be relatively equal across groups for a particular service, comparisons between groups would not be affected. Additionally, the true magnitude of pneumonia cost has yet to be fully addressed given the focus of this study on direct costs.

\section{Conclusion}

This study demonstrated higher health care resource utilization and costs in patients with COPD after acquiring pneumonia. Careful monitoring of COPD patients at risk of developing pneumonia is recommended. By reducing the risk of pneumonia in patients with COPD wherever possible, significant benefits to patients with COPD and resulting savings to our health care system can be realized.

\section{Acknowledgments}

We thank Write All, Inc., the company that provided editorial and written services on behalf of Novartis Pharmaceuticals Corporation.

\section{Author contributions}

Junji Lin, Yunfeng Li, Haijun Tian, Michael J Goodman, Susan Gabriel, Tara Nazareth, Stuart J Turner, Stephen Arcona, and Kristijan H Kahler were involved in the initiation of the study and in the definition of the study objective and search strategy. Each of the authors also aided in conducting the study analysis and interpreting the study results and wrote and critically reviewed the manuscript. All authors have read and approved the entire manuscript, and are accountable for all aspects of the work.

\section{Disclosure}

Junji Lin was a Novartis Data Analytics Fellow at University of Utah and Stuart J Turner was a Novartis Outcomes Research Fellow at Rutgers University. Both Fellows did this research as a part of their Fellowship and were both funded by Novartis Pharmaceuticals Corporation. Yunfeng Li, Haijun Tian, Susan Gabriel, Tara Nazareth, Stuart J Turner, Stephen Arcona, and Kristijan H Kahler are employees of Novartis Pharmaceuticals Corporation. Michael J Goodman is an assistant professor in the Department of Pharmacotherapy at the University of Utah. Written and editorial support for the preparation of this manuscript was provided by Write All, Inc., who received funding for services from Novartis Pharmaceuticals Corporation. The authors report no other conflicts of interest in this work.

\section{References}

1. The World Health Report 2000. Health Systems: Improving Performance. Available from: http://www.who.int/whr/2000/en/whr00_en.pdf. Geneva: World Health Organization; 2000. Accessed July 17, 2013.

2. Yawn BP, Li Y, Tian H, Zhang J, Arcona S, Kahler KH. Inhaled corticosteroid use in patients with chronic obstructive pulmonary disease and the risk of pneumonia: a retrospective claims data analysis. Int $J$ Chron Obstruct Pulmon Dis. 2013;8:295-304.

3. Ernst P, Gonzalez AV, Brassard P, Suissa S. Inhaled corticosteroid use in chronic obstructive pulmonary disease and the risk of hospitalization for pneumonia. Am J Respir Crit Care Med. 2007;176(2):162-166.

4. Marzoratti L, Iannella HA, Waterer GW. Inhaled corticosteroids and the increased risk of pneumonia. Ther Adv Respir Dis. 2013;7(4):225-234.

5. Price D, Yawn B, Brusselle G, Rossi A. Risk-to-benefit ratio of inhaled corticosteroids with COPD. Prim Care Respir J. 2013;22(1):92-100.

6. Crim C, Calverley PM, Anderson JA, et al. Pneumonia risk in COPD patients receiving inhaled corticosteroids alone or in combination: TORCH study results. Eur Respir J. 2009;34(3):641-647. 
7. Calverley PM, Stockley RA, Seemungal TA, et al; Investigating New Standards for Prophylaxis in Reduction of Exacerbations (INSPIRE) Investigators. Reported pneumonia in patients with COPD: findings from the INSPIRE study. Chest. 2011;139(3):505-512.

8. Lopez AD, Mathers CD, Ezzati M, Jamison DT, Murray CJ. Global and regional burden of disease and risk factors, 2001: systematic analysis of population health data. Lancet. 2006;367(9524):1747-1757.

9. Ewig S, Birkner N, Strauss R, et al. New perspectives on communityacquired pneumonia in 388406 patients. Results from a nationwide mandatory performance measurement programme in healthcare quality. Thorax. 2009;64(12):1062-1069.

10. Holguin F, Folch E, Redd SC, Mannino DM. Comorbidity and mortality in COPD-related hospitalizations in the United States, 1979 to 2001. Chest. 2005;128(4):2005-2011.

11. Polsky D, Bonafede M, Suaya JA. Comorbidities as a driver of the excess costs of community-acquired pneumonia in US commerciallyinsured working age adults. BMC Health Serv Res. 2012;12:379.

12. Liu SX, Lee MC, Atakhorrami M, et al. Economic assessment of homebased COPD management programs. COPD. 2013;10(6):640-649.

13. Breunig IM, Shaya FT, Scharf SM. Delivering cost-effective care for COPD in the USA: recent progress and current challenges. Expert Rev Pharmacoecon Outcomes Res. 2012;12(6):725-731.

14. Birnbaum HG, Morley M, Greenberg PE, Cifaldi M, Colice GL. Economic burden of pneumonia in an employed population. Arch Intern Med. 2001;161(22):2725-2731.

15. Örnek T, Tor M, Altin R, et al. Clinical factors affecting the direct cost of patients hospitalized with acute exacerbation of chronic obstructive pulmonary disease. Int J Med Sci. 2012;9(4):285-290.

16. Truven Health Analytics [homepage on the Internet]. Ann Arbor, MI: Truven Health Analytics Inc.; 2012. Available from: http://truvenhealth. com/your_healthcare_focus/research/marketscan_research_databases. aspx. Accessed July 17, 2013.

17. Centers for Disease Control and Prevention [homepage on the Internet]. International Classification of Diseases, Ninth Revision, Clinical Modification (ICD-9-CM). Atlanta, GA: Centers for Disease Control and Prevention; 2014. Available from: http:/www.cdc.gov/nchs/icd/ icd $9 \mathrm{~cm} . \mathrm{htm}$. Accessed September 3, 2013.
18. Halbert RJ, Natoli JL, Gano A, Badamgarav E, Buist AS, Mannino DM. Global burden of COPD: systematic review and meta-analysis. Eur Respir J. 2006;28(3):523-532.

19. Deyo RA, Cherkin DC, Ciol MA. Adapting a clinical comorbidity index for use with ICD-9-CM administrative databases. J Clin Epidemiol. 1992;45(6):613-619.

20. Austin PC. Balance diagnostics for comparing the distribution of baseline covariates between treatment groups in propensity-score matched samples. Stat Med. 2009;28(25):3083-3107.

21. Baser O, Crown WH, Pollicino C. Guidelines for selecting among different types of bootstraps. Curr Med Res Opin. 2006;22(4): 799-808.

22. Chronic Obstructive Pulmonary Disease (COPD) Includes: Chronic Bronchitis and Emphysema [webpage on the Internet]. Atlanta, GA: Centers for Disease Control and Prevention; 2012 [updated May 14, 2014]. Available from: http://www.cdc.gov/nchs/fastats/copd.htm. Accessed July 17, 2013

23. Yu H, Rubin J, Dunning S, Li S, Sato R. Clinical and economic burden of community-acquired pneumonia in the Medicare fee-for-service population. J Am Geriatr Soc. 2012;60(11):2137-2143.

24. Broulette J, Yu H, Pyenson B, Iwasaki K, Sato R. The incidence rate and economic burden of community-acquired pneumonia in a working-age population. Am Health Drug Benefits. 2013;6(8):494-503.

25. Müllerova $\mathrm{H}$, Chigbo $\mathrm{C}$, Hagan $\mathrm{GW}$, et al. The natural history of community-acquired pneumonia in COPD patients: a population database analysis. Respir Med. 2012;106(8):1124-1133.

26. Global Strategy for the Diagnosis, Management, and Prevention of Chronic Obstructive Pulmonary Disease. Global Initiative for Chronic Obstructive Lung Disease (GOLD) [updated 2014]. Available from: http://www.goldcopd.org/guidelines-global-strategy-for-diagnosismanagement.html. Accessed April 7, 2014.
ClinicoEconomics and Outcomes Research

\section{Publish your work in this journal}

ClinicoEconomics \& Outcomes Research is an international, peerreviewed open-access journal focusing on Health Technology Assessment, Pharmacoeconomics and Outcomes Research in the areas of diagnosis, medical devices, and clinical, surgical and pharmacological intervention. The economic impact of health policy and health systems

\section{Dovepress}

organization also constitute important areas of coverage. The manuscript management system is completely online and includes a very quick and fair peer-review system, which is all easy to use. Visit http://www.dovepress.com/testimonials.php to read real quotes from published authors. 